\title{
Some observations on the Poggendorff and Müller-Lyer tactual illusions
}

\author{
ALBINA LUCCA, ANNA DELLANTONIO, and LUCIA RIGGIO \\ University of Padua, Padua, Italy
}

\begin{abstract}
Two experiments were conducted in which illusory and nonillusory figures were presented in the right and left tactual fields. Experiment 1 used 24 men (aged 18-24 years) and the Poggendorff (P) illusion and an alignment (Al) task; Experiment 2 used another 24 men and the MüllerLyer (ML) illusion and a line-match ( $\mathrm{Lm}$ ) task. Standard and mirror-image presentations of the figure were used in each case. Nested designs of analysis of variance and analysis of covariance were adopted for comparing left- and right-hand performance under each experimental condition. Covariance analysis on distortion scores of $\mathrm{P}$ and $\mathrm{ML}$ was performed separately with discrepancy measures on $\mathrm{Al}$ and $\mathrm{Lm}$ tasks as covariates. An investigation was also made into whether the direction of tactually perceived distortions was the same as or opposite to that reported for the visual illusions. The results show large $P$ and ML tactual distortions. For ML, the tactual effects found were similar to those predictable from visual illusions, whereas for $P$, a high value of inversion emerged. Differences between hands were significant for $\mathrm{P}$ under the standard presentation, exploration with the right hand inducing a higher value of inversion. The latter results are discussed with reference to differences between the functions of human hemispheres which some authors have suggested for perceptual distortions.
\end{abstract}

Susceptibility to visual illusions has been only marginally investigated in the context of functional hemispheric lateralization studies. As is well known, human hemisphere functioning is described in terms of contrasting modes of cognition, information processing, and coding (e.g., Bradshaw \& Nettleton, 1981). According to the most current formulation, the left hemisphere may use analytic, serial, or sequential strategies, while the right uses global or parallel strategies (Simion \& Bagnara, 1982); other studies point out the differences in coding information (Posner, 1978; Umiltà, 1982). Friedman and Campbell-Polson (1981) proposed a model of the hemispheres as two independent and limited pools of resources, or subprocessors (Allen, 1983), which could be used in different ways. Whatever mechanism underlies the experimental data, however, there is general agreement that the left hemisphere is verbal, while the right is visuospatial. Basso, Bisiach, and Faglioni (1974) proposed that if illusions were due to perceptual distortion depending on structural features of a particular stimulus, right-hemisphere damage, by impairing the holistic attitude, should reduce susceptibility to the illusion, and left-hemisphere damage should enhance it. Basso et al. therefore studied performance in a linear-lengthdiscrimination task and the extent of the Müller-Lyer (ML)

This research was supported by a grant from the Italian Ministry of Public Instruction to the University of Padua. The authors are grateful to Fabio Metelli, Carlo Umiltà, and the anonymous referees for comments useful in structuring the underlying issues. Thanks are also extended to U. Toffano for his technical help. The authors' mailing address is: Department of General Psychology, University of Padua, Piazza Capitaniato 3, 35139 Padua, Italy. visual illusion in normal and unilateral-brain-damaged patients.

Although linear-length discrimination was found to be impaired in right-brain-damaged patients with a visual field defect, Basso et al. found that, contrary to the hypothesis, left-brain-damaged patients showed reduced susceptibility to the ML. A second study, performed by Houlard, Fraisse, and Hecaen (1976) on the effects of unilateral hemispheric lesions on two visual illusions (Ponzo and ML), gave opposite results for the ML. Houlard et al. had conjectured that, if the right hemisphere "subserves visuo-spatial functions and engages in global synthetic processing" (p. 232), one might predict that right lesions, in disturbing normal perception, "would reduce or abolish illusions when they involve a perceptual activity relating distinct parts" (p. 233), as in the Ponzo illusion. In contrast, left-sided lesions should " augment illusion when it results from a primary field effect (or from assimilation)"' (p. 233), as for ML. Houlard's results are ambiguous and contrast with those quoted above (Basso et al., 1974): patients with left-sided lesions have stronger illusions than normal subjects (this result was significant for the $\mathrm{ML}$ ), whereas in right-braindamaged subjects the Ponzo is weakened and the ML is equivalent to that of control subjects. On the same line, Clem and Pollack (1975) showed that, in normal subjects, when the figural parts of the visual ML illusion are presented simultaneously in the left visual field (right hemisphere), the magnitude of the illusion is significantly greater than when the same parts are presented in the right visual field (left hemisphere); on the other hand, if the presentation is successive, the illusion is greater for the left hemisphere. 
Since the issue has been unresolved, we tried to study it in normal subjects, using Poggendorf (P) and ML figures, which are, by general agreement, very different; the first generates a distortion of direction, and the second generates one of linear extension (Coren, Girgus, Erlichman, \& Hakstian, 1975; Robinson, 1972). Moreover, we chose to use these figures in their tactual form. As Revesz's work (1934) pointed out, illusions also take place when the stimulus figure is explored tactually (e.g., haptically in sequential succession), and, accordingly, Metzger, Vukotich-Voth, and Koch (1970) wrote about opticotactual illusions (see also Calabresi, 1932; Costa, 1937; Dellantonio, Riggio, \& Crolle, 1982; Fry, 1975; Hatwell, 1960; Rudel \& Teuber, 1963). A tactual task might be helpful in this research, because righthemisphere spatial superiority has been demonstrated using tactual exploration of nonsense shapes (e.g., Witelson, 1974) and in tactual tests involving orientation of segments (e.g., for normal subjects, Benton, Varney, \& Dehamsher, 1978; Oscar-Berman, Rehbein, Porfert, \& Goodglass, 1978; for brain-damaged subjects, De Renzi, Faglioni, \& Scotti, 1971; De Renzi, 1982). It seemed reasonable that in tactual illusion tasks also directional components should be processed by the right hemisphere.

Furthermore, results from neurophysiological research support the points just mentioned: the postcentral gyrus of the neocortex (somatosensory area I) contains neurons that have directional sensitivity, and this population of direction-sensitive neurons probably contributes fundamentally to the ability of primates to judge and respond appropriately to the direction of tactually explored stimuli (Hyvarinen, 1976); moreover, the cortical areas of contralateral representation of the hand are substantially lacking in callosal connections (Roland, Larsen, Lassen, \& Skinhoj, 1980), and are, hence, to a considerable extent, independent, at least as regards the initial stages of information processing, making it more likely that differences in performance will emerge between the two hemispheres-as the results mentioned above suggest.

On the basis of these considerations and of the results of preliminary studies carried out in order to investigate the degree and frequency of certain tactile distortions (Dellantonio, Lucca, \& Riggio, 1984), we formulated the hypothesis that the degree of perceptual distortion induced by tactile exploration of the $P$ figure is lower for the left hand (right hemisphere). In fact, if it is true that correlations between the parts of a visuospatial context are detected more accurately by the right hemisphere than the left, the number and degree of the distortions typically found for the stimulus figure should be smaller when the $P$ figure is explored by the left hand, especially since this illusion seems to involve a directional component. This hypothesis can be supported by the results already cited, which show how the left hand is more efficient than the right in certain tasks that involve orientation of segments.

Differences between the two hands should, however, be smaller for exploration of the ML figure, which requires a comparison between segment lengths and does not seem to involve a directional component. Moreover, as Clem and Pollack's (1975) data suggest, the right hand (left hemisphere) would be more susceptible than the left to $P$ and ML tactile illusions, because sequential modes of collecting information by the hand may interact with functional demands in determining the hemispheric locus of data processing. This difference might emerge more clearly with $\mathrm{P}$ figures which involve a directional component.

Two experiments were conducted here. The purpose of Experiment 1 was to study haptic perception of the $\mathbf{P}$ illusion and of a simple alignment (Al) effect (see Figures 1 and 2). In this experiment, we asked ourselves (1) whether perceptual distortions would be found, and in particular, whether there would be a difference between distortions obtained when exploring the $P$ figure and those obtained when the two segments were considered in a simple alignment task; (2) whether there was a perceptual asymmetry between the right and left hands for the P distortion and in the errors for an alignment task; and (3) whether this asymmetry, when it exists, would be found in both standard and mirror image presentations of the figures, which might affect the exploration strategies of each hand differently.

In Experiment 2, attention was focused on the ML figure and a line-match (Lm) task (see Figure 6). In this experiment, the aim was to investigate, for the tactile ML figure, (1) whether the results again would confirm the presence of perceptual distortions and, in particular, whether a significant difference would be obtained between the condition in which the two segments of the illusions were compared and the condition in which the segments were compared outside the illusion context; (2) whether, in both of the preceding tasks, performance of the right hand would differ from that of the left; and (3) whether such asymmetry would occur in the standard and in the mirror-image presentation of the ML figure.

\section{EXPERIMENT 1}

In this experiment, the focus of attention was the $P$ figure and the $\mathrm{Al}$ task.

\section{Method}

Subjects. The subjects were 24 male university students, 18-24 years of age (mean 21 years 6 months); they were all right-handed, according to Oldfield's (1971) test.

Stimuli. The stimulus patterns shown in Figures 1 and 2 were constructed using 2-mm-thick aluminum strips.

Two symmetrical forms were constructed for each of both the $\mathrm{P}$ and the Al figures, so as to eliminate the possibility that manual exploration might favor one or the other of these forms.

The stimuli (Figures 1 and 2) were constructed by fixing the aluminum strips into a suitable indented wooden base $(8 \times 15 \mathrm{~cm})$. Segments $a$ and $b$ were $5 \mathrm{~cm}$ long, and the inclination angle was $45^{\circ}$. The parallel lines were $9.7 \mathrm{~cm}$ long and $1 \mathrm{~cm}$ apart. All strips extended about $1 \mathrm{~mm}$ out from the base.

For the $\mathbf{P}$ figure and the $\mathrm{Al}$ task, the parts of Figures 1 and 2 marked $a$ were mobile, since the wooden block supporting segment $a$ could move in both directions.

Procedure. The subject was blindfolded and seated comfortably on a chair in front of a table on which the stimulus figures were placed one at a time. The surface of the subject's lower arms rested 


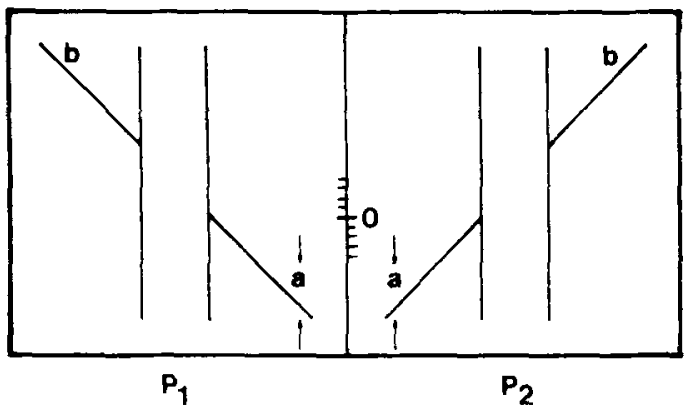

Figure 1. Stimuli used for the $P$ illusion in the standard $\left(P_{1}\right)$ and mirror-image $\left(\mathbf{P}_{2}\right)$ presentations.

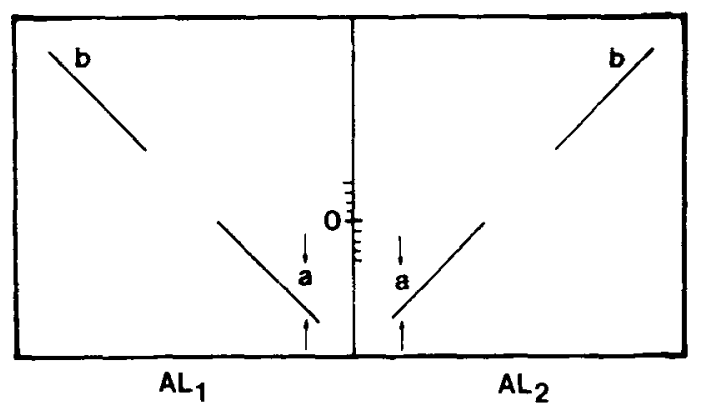

Figure 2. Stimuli used for the alignment (Al) task in the standard $\left(\mathrm{Al}_{1}\right)$ and mirror-image $\left(\mathrm{Al}_{2}\right)$ presentations.

on the table, where they were held still by two elastic bands; the hands, however, were free to explore. The experimenter sat in front of the blindfolded subject, on the opposite side of the table, and gave him the following instructions, which were the same for both the alignment task and the P figure: "Now you are going to use the tips of your index and middle finger to explore first segment $a$ and then segment $b$. You must decide whether $a$ is in line with $b$. If it isn't you must slide $a$ up and down until $a$ and $b$ are in line. You are only allowed to use the tips of your fingers. What interests us is how it seems to you, not whether your judgment is right or wrong." After five training trials, the experiment began. Stimulus $a$ was presented at displacements of $8,6,4$, and $2 \mathrm{~mm}$, both above and below point 0 (Figures 1 and 2); there were also two presentations at the 0 point, making for a total of 10 presentations in all. For each subject, the alignment task was presented in a random order, both in the nonillusion condition and in the illusion condition. The use of right or left hand to begin the exploration was determined according to the sequence RLLR. Judgments were always requested beginning with segment $a$, and, hence, the exploration always proceeded from $a$ to $b$; the subject was allowed as much time as he wished, up to a maximum of $15 \mathrm{sec}$.

For each of the four tasks $\left(\mathrm{P}_{1}, \mathbf{P}_{2}, \mathbf{A l}_{1}, \mathbf{A l}_{2}\right)$, each subject carried out 10 trials with the left hand and 10 with the right. The extent of the perceptual distortion was measured, in each case, by the distance in millimeters from the zero point. In this way, we calculated, for each block of 10 trials for each subject, the global distortion effect, the illusion effect (i.e., the distortion in the direction normally described for the visual modality), and finally the inversion effect (i.e., the effect in the opposite direction to that normally obtained for the visual illusion). This procedure of distinguishing the measurements was suggested from previous observations of the effect (Calabresi, 1932; Dellantonio et al., 1982). As will be obvious, the adjustment task was preferred because it does not involve verbal responses (see, e.g., Patterson \& Deffenbacher, 1972).

\section{Results}

Study of perceptual asymmetries within the $P$ illusion and the alignment task. The same statistics were calculated to evaluate performance in the two tasks.

First, for a preliminary analysis, only absolute discrepancies were computed; that is to say, underestimations and overestimations were considered as identical. Table 1 presents mean and standard deviations of absolute discrepancy scores (distortion effects) for each hand with right and left presentation for each task.

The scores were compared by an analysis of variance. Comparison between left- and right-hand conditions when the two different sides were presented within the two tasks is of fundamental importance for inferences regarding the present study. To compare mean individual differences under each experimental condition, a completely nested design of ANOVA was adopted (see, e.g., Keppel, 1973; Marascuilo \& Levin, 1970, 1976) with three fixed-effect factors: $S$, stimuli $\left(s_{1}=\mathrm{P}, s_{2}=\mathrm{Al}\right), C$ nested within $S$, sides of presentation of the stimuli $\left(c_{1}=\mathrm{P}_{1}\right.$ and $c_{2}=\mathrm{P}_{2}$ for $\mathrm{P}$, $c_{1}=\mathrm{Al}_{1}$ and $c_{2}=\mathrm{Al}_{2}$ for $\left.\mathrm{Al}\right)$ and $T$ within $C(S)$, tactual fields (left and right hand stimulation) for each side presented within the two stimuli; all the factors were within-subjects variables.

There was a highly significant ${ }^{1}$ distortion effect on the $P$ figure relative to the degree of error on the alignment task $[F(1,23)=114.86, p<.0001]$. The side of presentation did not affect distortion scores significantly. The main tactual field effect nested within $C(S)$ was significant $[F(4,92)=2.30, p<.10]$. Appropriate post hoc comparison for nested hypotheses ${ }^{2}$ (see Marascuilo \& Levin, 1970, 1976) showed that: (1) with the Al figure, the left-hand-right-hand difference was not significant for either of the sides presented, and (2) with the P figure, the left-hand-right-hand difference was significant for the $\mathrm{P}_{1}$ side of presentation $[F(1,92)=7.47, p<.01]$; point estimation showed greater right-hand distortion.

The directional similarity between tactual and visual distortions was also considered. For the $\mathbf{P}$ task, the overall mean proportion $P(E)$ of expected errors, that is to say, of errors in the direction of the comparable visual illusions, was equal to .22 , whereas the overall mean proportion $P(I)$ of inversions exceeded .66. However, for the Al task, errors in the two opposite directions did not differ significantly, with $P(E)=.27$ and $P(I)=.35$.

Table 1

Discrepancy Means and Standard Deviations of Absolute Discrepancy Scores in Experiment 1

\begin{tabular}{|c|c|c|c|c|c|c|c|c|}
\hline \multirow[b]{3}{*}{ Hand } & \multicolumn{4}{|c|}{$P$} & \multicolumn{4}{|c|}{$\mathrm{Al}$} \\
\hline & \multicolumn{2}{|c|}{$P_{1}$} & \multicolumn{2}{|c|}{$P_{2}$} & \multicolumn{2}{|c|}{$\mathrm{Al}_{1}$} & \multicolumn{2}{|c|}{$\mathrm{Al}_{2}$} \\
\hline & Mean & $\mathrm{SD}$ & Mean & $\mathrm{SD}$ & Mean & SD & Mean & SD \\
\hline $\mathbf{R}$ & 4.27 & 2.06 & 4.16 & 2.37 & .95 & .38 & .81 & .54 \\
\hline L & 3.31 & 1.50 & 4.40 & 1.94 & .89 & .47 & 1.11 & .61 \\
\hline
\end{tabular}

Note-Scores given in millimeters for right (R) and left (L) hands under standard $\left(\mathrm{P}_{1}\right)$ and mirror-image $\left(\mathrm{P}_{2}\right)$ sides of presentation for the Poggendorff (P) figure and under $\mathrm{Al}_{1}$ and $\mathrm{Al}_{2}$ sides of presentation for the simple alignment ( $\mathrm{Al})$ task. 
To examine the direction of distortion for both the $P$ figure and the $\mathrm{Al}$ task, positive signs were attached to distances (in millimeters) from zero point in the same direction as the comparable visual illusion; negative signs were assigned to discrepancies in the direction opposite to that obtained with vision. Plus scores (positive illusion effects) and minus scores (inversion effects) were analyzed separately (see, e.g., Pasnak \& Ahr, 1970) so that the directional similarity to vision might be examined. Mean illusion scores and mean inversion scores are shown, respectively, in Figures 3 and 4.

Positive and negative discrepancies were explored by means of the completely nested model of ANOVA previously used for the preliminary analysis of absolute discrepancies.

As regards positive illusion effects, only the difference between the $P$ illusion and the corresponding performance on the Al task turned out to be significant $[F(1,23)=5.52$, $M S e=1.61, p<.05]$.

Analysis of the inversion scores confirmed previous data obtained on absolute discrepancies. The $S$ effect was highly significant $[F(1,23)=63, M S e=5.25$, $p<.001]$. Moreover, the inversion effect with the righthand stimulation was significantly different from the performance with the left hand only for the $P$ figure under the $\mathrm{P}_{1}$ side of presentation $[F(1,92)=4.69, M S \mathrm{e}=2.19$,

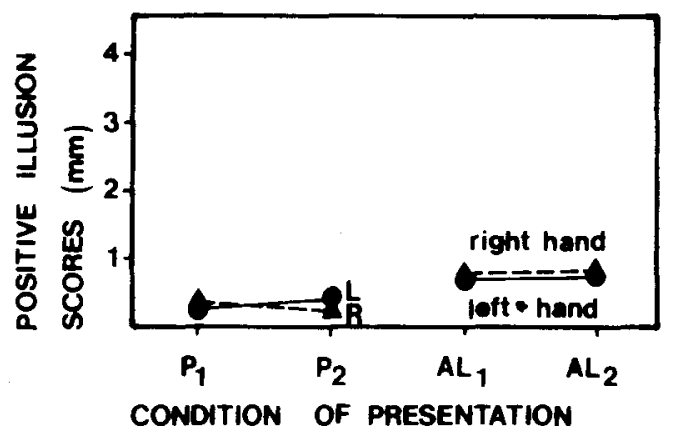

Figure 3. Mean positive illusion scores (in millimeters) for $\mathrm{P}$ and Al tasks under $\mathbf{P}_{1}, \mathbf{P}_{2}, \mathbf{A l}_{1}, \mathbf{A l}_{2}$ conditions for right (R) and left (L) hands.

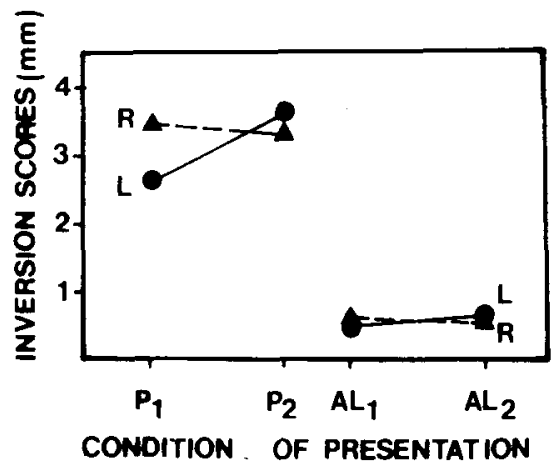

Figure 4. Mean inversion scores (in millimeters) for $P$ and $A l$ tasks, under $P_{1}, P_{2}, A l_{1}$, and $A l_{2}$ conditions for $R$ and $L$ hands.

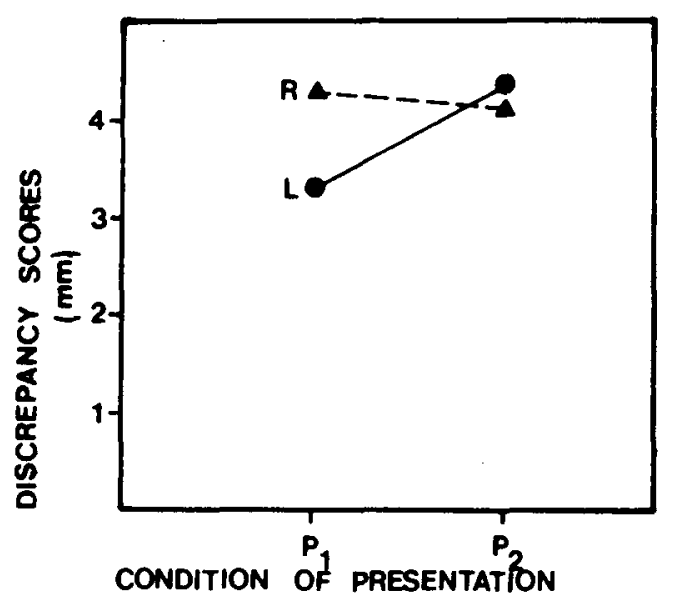

Figure 5. Mean adjusted values for absolute discrepancy scores for the $P$ tasks under $P_{1}$ and $P_{2}$ conditions for $R$ and $L$ hands.

$p<.05$ ]; from point estimation, a greater inversion emerged for the right hand.

Contribution to Poggendorf distortion of a more generalized deficit in the alignment task. In order to determine whether any observed differences that might obtain between hands and side presented could be attributed to difficulties associated with the perceptual illusion or to a more generalized deficit in the alignment of two segments, distortion scores on the $P$ figure were further analyzed with discrepancy scores on the Al task as a covariate (e.g., Myers, 1979, chap. 12).

First, absolute discrepancy scores on the P figure were compared by an analysis of covariance with two withinsubjects factors $(C$, sides of presentation: $T$, tactual fields within $C$ ), concomitant variables being absolute discrepancies on the Al figure.

The mean adjusted values are shown in Figure 5.

The analysis confirmed all the results of the first analysis of variance. There was a significant $T$-within- $C$ effect due to the difference between hands under the $P_{1}$ side presentation $[F(1,44)=4.15, p<.05]$.

Moreover, covariance analyses were performed on positive illusion effects and on inversion scores on the $P$ figure with the discrepancies in the corresponding directions on the Al figure as covariates. These analyses yielded the same results as the previous comparable ANOVAs.

\section{EXPERIMENT 2}

In this experiment, subjects were required to explore tactually the two ML figures and a simple line-match (Lm) figure (Figure 6). The illusory figures were the Von Brentano versions of the ML constructed with aluminum strips, $2 \mathrm{~mm}$ thick, fixed in a wooden base from which they extended about $1 \mathrm{~mm} ; a$ and $b$ were $4 \mathrm{~cm}$ long; the inside arrowhead could be moved in either direction from 0 . The dimensions were similar in the stimuli for the $\mathrm{Lm}$ task. 


\section{Method}

Subjects. The subjects were another group of 24 students with the same characteristics as those used in the first experiment.

Procedure. For Experiment 2, the procedure was partially analogous to that of Experiment 1; the instructions, however, were different. For the task of comparing the two segments, both in the nonillusion condition and in the illusion condition, the subject was told: "With this hand you can touch two segments. You must move the index, guiding your hand in such a way that, in your judgment, segment $a$ becomes equal to segment $b$. What interests us is how it seems to you, not whether your judgment is right or wrong." The index was presented in the (randomized) positions of $8,6,4$, and $2 \mathrm{~mm}$, both the left and the right of the 0 point (Figure 5); the 0 position was also presented, twice, making for a total of 10 presentations in all.

For each task, the subject carried out 10 trials with the left hand and 10 with the right. The extent of the perceptual distortion was measured as in Experiment 1.

\section{Results}

Study of perceptual asymmetries within the MüllerLyer illusion and the line-match task. Table 2 presents mean and standard deviations of absolute discrepancy scores for each hand for the ML figure at different sides of presentation and for the Lm task.

When scores were compared with ANOVA, only a significant distortion effect on the ML figure relative to the degree of error on the $\mathrm{Lm}$ figure emerged. This result confirmed previous data on comparable visual tasks (see Barton, 1969).

Then discrepancies in the direction predicted by vision (positive illusion scores) and discrepancies in the direction opposite to vision (inversion scores) were calculated; the corresponding mean values are represented, respectively, in Figures 7 and 8.

It should be noted that distortion effects were consistent with the direction of comparable visual findings. These results confirmed previous data (e.g., Dellantonio et al., 1984; Dellantonio et al., 1982; Fry, 1975).

There was a significant illusion effect on the ML figure related to the degree of error in the $\mathrm{Lm}$ task. In the present study, no left-hand-right-hand differences were significant.

Covariance analyses on the ML data with Lm scores

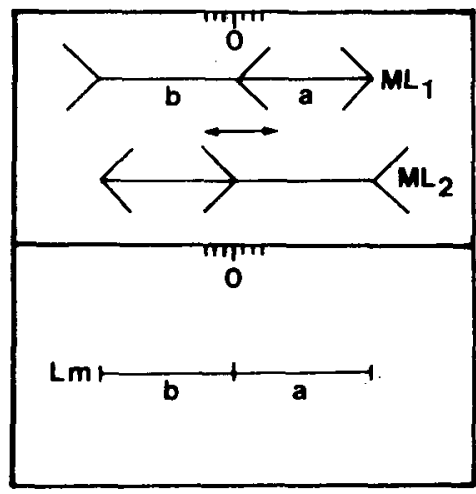

Figure 6. Stimuli used for the Müller-Lyer (ML) illusion in $M L_{1}$ and $\mathrm{ML}_{2}$ conditions of presentation and stimulus used for the linematch (Lm) task.
Table 2

Discrepancy Means and Standard Deviations of Absolute Discrepancy Scores in Experiment 2

\begin{tabular}{|c|c|c|c|c|c|c|}
\hline \multirow[b]{3}{*}{ Hand } & \multicolumn{4}{|c|}{ ML } & \multicolumn{2}{|c|}{$\mathbf{L m}$} \\
\hline & \multicolumn{2}{|c|}{$\mathrm{ML}_{1}$} & \multicolumn{2}{|c|}{$\mathrm{ML}_{2}$} & \multicolumn{2}{|c|}{$\mathrm{Lm}_{1}=\mathrm{Lm}_{2}$} \\
\hline & Mean & $\overrightarrow{\mathrm{SD}}$ & $\overline{\text { Mean }}$ & $\overline{\mathrm{SD}}$ & Mean & $\overline{\mathrm{SD}}$ \\
\hline $\mathbf{R}$ & 3.16 & 1.31 & 3.00 & 1.35 & 1.69 & .44 \\
\hline $\mathrm{L}$ & 2.92 & 1.23 & 3.08 & 1.04 & 1.58 & .44 \\
\hline
\end{tabular}

Note-Scores given in millimeters for right $(R)$ and left $(L)$ hands under $M L_{1}$ and $M L_{2}$ sides of presentation for the Müller-Lyer (ML) figure and on the line-matching $(\mathrm{Lm})$ task.

as covariates confirmed the results obtained on the corresponding ANOVAs.

\section{GENERAL DISCUSSION}

Certain conclusions can be drawn from this study. The two experiments that have been described (the first relating to the $P$ figure in comparison with the alignment task, the second relating to the ML figure in comparison wih the segment comparison task) show that the $\mathrm{P}$ and ML figures, when explored with the fingertip, induce a considerable degree of distortion-a distortion that is significantly greater than the subjective error that occurs for an analogous, but nonillusory, perceptual task. This result confirms the view, already mentioned, that tactile illusions are possible.

The analyses also confirm two interesting details already noted in Dellantonio et al. (1984). The first is that the two different mirror-image conditions of the stimuli (Figures 1 and 2 and Figure 6) do not, in themselves, seem to play any role in determining the overall extent of the nonillusory subjective errors or of the distortions in all conditions - that is, both for the illusions and the inversions. The second is that for the tactile form of the $P$ figure, the distortion is obtained prevalently in the opposite direction to that normally described for the visual modality (Figures 3 and 4) (see also Calabresi, 1932; Costa, 1937; Pasnak \& Ahr, 1970). For the ML, on the other hand, the distortion occurs in the same direction as for the visual illusion (Figures 7 and 8).

As for the unimportance of the mirror-image conditions, it is evident that the nonillusory alignment task and the perceptual distortion induced by the tactile $\mathrm{P}$ figure are not influenced by variations in the global orientation of the oblique segments provided that all the other figural conditions are kept constant. In the same way, the segment comparison task in the tactile ML figure is not influenced by the relative positions of the open or closed arrows. These results suggest that structural context is important in determining distortion, and that the mirrorimage presentation of the figure has little effect.

Concerning the inversions noted for the tactile $P$ figure, it should be remembered that Fry (1975), using other tactile illusions, and Calabresi (1932), Costa (1937), and Pasnak and Ahr (1970), using the P illusion itself, have already described analogous phenomena: this "reversal" acquires special importance when one considers that in 


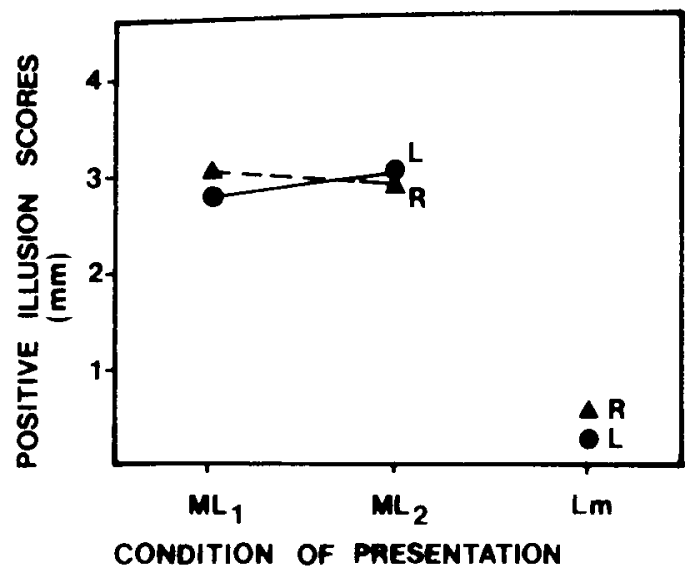

Figure 7. Mean positive illusion scores (in millimeters) for the ML task in $M L_{1}$ and $M L_{2}$ conditions and for the $L m$ task for $R$ and $L$ hands.

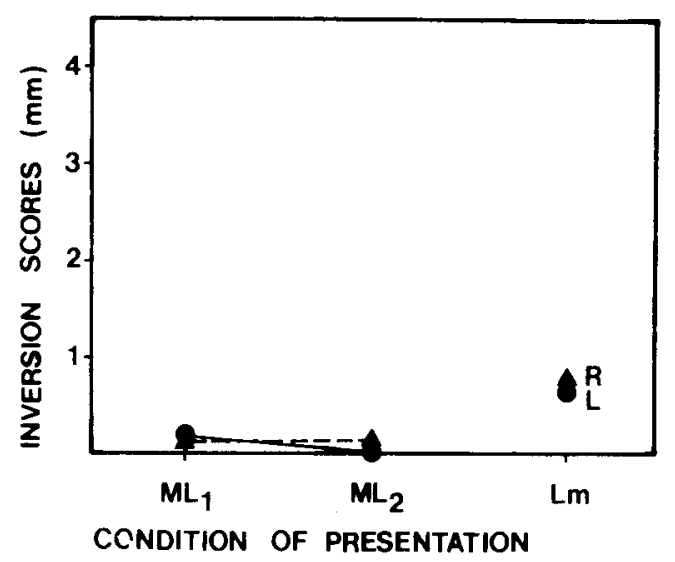

Figure 8. Mean inversion scores (in millimeters) for ML and Lm tasks.

the simple alignment task these inversions are slight and smaller than the discrepancies in the opposite direction (Figures 3 and 4).

Elsewhere (Dellantonio et al., 1982), we have tried to explain the frequency of such inversions on the basis of the fact that exploration of the tactile $P$ figure is often limited to the acute angles where the oblique lines meet the parallel lines (the subjects' fingers repeatedly touch the sides in the vicinity of the intersection). In the visual modality, the modification of the $P$ illusion, known as the Restle figure, consists, in essence, of two acute angles and often produces a distortion in the opposite direction to that normally described for the visual $P$ illusion: perhaps, then, the tactile exploration strategy for the $P$ figure induces perceptual phenomena comparable to those found for the visual Restle figure. Another possibility that cannot be excluded is a mechanism of the alignmentdisplacement-effect type like that suggested by Hotopf (1981) to justify certain anomalies of optical illusions. By contrast, the phenomenon is not obtained for the tactile
ML, the direction of which corresponds to that obtained with the visual modality.

Remaining to be discussed is the difference between the two hands, which, as we have seen, proved to be significant only for the $P$ figure, while, instead, the mean error in millimeters is more or less the same for each hand in the nonillusory alignment task (Table 1). The latter result is predictable, since, as already pointed out, differences between the hands for tasks of this type have never been described in the literature, either for normal or for braindamaged subjects.

On the other hand, in the perceptual distortion of the $P$ figure, the performance of the hands, measured in millimeters of global displacement of segment $a$ with respect to the straight line to which $b$ also belongs (Figure 1), is differentiated: the right hand distorts significantly more than the left, as predicted by our hypothesis and by Clem and Pollack's (1975) results on successive presentation of visual illusory stimuli described above-but only in condition $\mathrm{P}_{\mathbf{1}}$.

To be precise, right- and left-hemisphere performances are roughly equivalent in $\mathbf{P}_{2}$, but the right one is less susceptible to illusion than left in $P_{1}$.

But why only in the $P_{1}$ condition? So far, no satisfactory explanation has been found. There appear to be no appreciable differences in the movements of the right and left hands while exploring the stimuli and in adapting them, either with the $\mathbf{P}$ figures or with the figures without parallel lines. These movements are successive and consist in feeling the segments lightly for some time, especially near the angles in P. It seems unlikely, even if it cannot be altogether ruled out, that the significance of the difference depends on the two hands' using different strategies during exploration. If this were the case, the difference ought also to appear in the nonillusory alignment task. Yet, neither the data on the effects of compatibility (e.g., Withaker, 1982) nor those on the asymmetries that may arise in perceptual distortions (e.g., Wenderoth \& Johnson, 1981, who quote Hotopf, personal communication, 1980) provide any indications that would help us to interpret our result. Moreover, we are forced to exclude any "effect of hemispace" (McFarland, 1982) in which performance depends not so much upon the hands involved as on where they are located in extracorporeal hemispace, because-as is well known-there has been little success in demonstrating hemispace effects in the tactual modality (Bradshaw, Nathan, Nettleton, Pierson, \& Wilson, 1983; Bradshaw, Nettleton, Nathan, \& Wilson, 1983).

Further work, using more refined experimental techniques that permit measurement of the precise exposure time or the number of movements involved in the exploration, should shed more light on the strategies involved in the tasks. Meanwhile, it cannot be excluded that the greater susceptibility of the right hand (left hemisphere) in $P_{1}$ may represent a clue in support of our hypothesis.

If so, the alignment task, with its directional components, is not sufficient to bring out the differences between 
hemispheres; it is the perceptual organization of the $\mathbf{P}_{1}$ figure which shows that the left hemisphere is more susceptible to illusion. These interpretations seem to us to be confirmed by the analysis of covariance, which shows that the differences between the right and left hands do not depend at all on the errors committed in a simple alignment task (Figure 5).

For the ML figure, on the other hand, the present study did not find hand differences in any of the mirror-image stimulus conditions. This appears to confirm the idea that the differences between hemispheres, in these cases, tend to emerge when the tactile spatial task is made more complex by its directional components.

\section{REFERENCES}

Allen, M. (1983). Models of hemispheric specialization. Psychological Bulletin, 93, 73-103.

Barton, M. (1969). Perception of the Mueller-Lyer illusion in normal and aphasic adults. Perceptual \& Motor Skills, 28, 403-406.

Basso, A., Bisiach, E., \& Faglioni, P. (1974). The Mueller-Lyer illusion in patients with unilateral brain damage. Cortex, 9, 26-35.

Benton, A. L., Varney, N. R., Dehamsher, K. (1978). Lateral differences in tactile directional perception. Neuropsychologia, 14, 175-181.

Bradshaw, J. L., Nathan, G., Nettleton, N. C., Pierson, I. M., \& WILSON, L. E. (1983). Head and body hemispace to left and right. III: Vibrotactile stimulation and sensory and motor components. Neuropsychologia, 12, 651-661.

Bradshaw, J. L., \& Nettleton, N. C. (1981). The nature of hemispheric specialization in man. Behavioral \& Brain Sciences, 4, 51-92.

Bradshaw, J. L., Nettleton, N. C., Nathan, G., \& Wilson, L. (1983). Head and body space to left and right, front and rear. II: Visuotactual and kinesthetic studies and left side underestimation. Neuropsychologia, 21, 475-486.

Calabresi, R. (1932). Contributo allo studio della illusione di Poggendorf. In Scritti di Psicologia raccolti in onore di Federico Kiesow. Torino, Italy: Istituto di Psicologia dell' Università.

Clem, R. K., \& Pollack, R. H. (1975). Illusion magnitude as a function of visual field exposure. Perception \& Psychophysics, 17, 450-454.

Coren, S., Girgus, J. S., Erlichman, H., \& Hakstian, A. R. (1975). An empirical taxonomy of visual illusion. Perception \& Psychophysics, 20, 129-137.

Costa, A. (1937). L'illusione di Poggendorff al tatto. Archivio Italiano di Psicologia, 15, 362-369.

Dellantonio, A., LucCA, A., \& Riggio, L. (1984). Asimmetrie tra le mani in alcune distorsioni percettive tattili. Giornale Italiano di Psicologia, 11, 537-556.

Dellantonio, A., Riggio, L., \& Crolle, M. V. (1982). Effetti di inversione nellillusione tattile di Poggendorff (Report No. 70). Padua, Italy: University of Padua, Institute of Psychology.

De Renzi, E. (1982) Disorders of space exploration and cognition. New York: Wiley.

De Renzi, E., Faglioni, P., \& Scotti, G. (1971). Judgement of spatial orientation in patients with focal brain damage. Journal of Neurological \& Neurosurgical Psychiatry, 34, 489-495.

Friedman, A., \& Camprell-Polson, M. (1981). Hemispheres as independent resource system: Limited capacity processing and cerebral specialization. Journal of Experimental Psychology: Human Perception \& Performance, 7, 1031-1058.

FRY, C. L. (1975). Tactual illusions. Perceptual \& Motor Skills, 40, 955-960.

Hatwell, Y. (1960). A study of geometrical tactile illusion among the blind. Année Fsychologique, 1, 11-27.

HотOPF, W. H. N. (1981). Mistracking in alignment illusions. Journal of Experimental Psychology: Human Perception \& Performance, 7, 1211-1246.
Houlard, N., Fraisse, P., \& Hecaen, H. (1976). Effects of unilateral hemispheric lesions on two types of optico-geometric illusions. Cortex, 12, 232-240.

Hyvarinen, J. (1976). Cellular mechanisms in the parietal cortex in alert monkey. In Y. Zotterman (Ed.), Sensory functions of the skin in primates. Oxford: Pergamon Press.

KePpel, G. (1973). Design and analysis. Englewood Cliffs, NJ: Prentice-Hall.

Marascuilo, L. A., \&evin, J. R. (1970). Appropriate post-hoc comparisons for interaction and nested hypotheses in analysis of variance designs: The elimination of type IV errors. American Educational Research Joumal, 7, 397-421.

Marascuilo, L. A., Levin, J. R. (1976). The simultaneous investigation of interaction and nested hypotheses in two-factor analysis of variance designs. American Educational Research Journal, 13, 41-65.

MCFARLAND, K. (1982). Effects of hemispace on concurrent task performance. Neuropsychologia, 20, 365-367.

Metzger, W., Vucotich-Voth, O., \& KoCH, I. (1970). Über optischhaptische Masstauschungen und dreidimensionalen Gegenständen. Psychologische Betreige, 12, 41-58.

MilleR, R. G. (1966). Simultaneous statistical inference. New York: McGraw-Hill.

MYERS, J. (1979). Fundamentals of experimental design. Boston: Allyn \& Bacon.

OLDFIELD, R. C. (1971). The assessment and analysis of handedness: The Edinburgh Inventory. Neuropsychologia, 9, 97-114.

Oscar-Berman, M., Rehbein, L., Porfert, A., \& Goodglass, H. (1978). Dichaptic hand order effects with verbal and non-verbal tactile stimulation. Brain \& Language, 6, 323-333.

Pasnak, R., \& Ahr, P. (1970). Tactual Poggendorff illusion in blind and blindfolded subjects. Perceptual \& Motor Skills, 31, 151-154.

Patterson, J., \& Deffenbacher, K. (1972). Haptic perception of the Mueller-Lyer illusion by the blind. Perceptual \& Motor Skills, 35, 819-824.

Posner, M. J. (1978). Chronometric exploration of mind. Hillsdale, NJ: Erlbaum.

REVESZ, G. (1934). System der optischen und haptischen Raumtauschungen. Zeitschrift für Psychologie, 131, 292-375.

RoBinson, J. O. (1972). The psychology of visual illusions. London: Hutchinson.

Roland, P. E., Larsen, B., Lassen, N. A., \& Skinhoj, E. (1980). Supplementary motor area and other cortical areas in organization of voluntary movements in man. Journal of Neurophysiology, 43, 118-136.

Rudel, R. G., \& Teuber, H. L. (1963). Decrement of visual and haptic Mueller-Lyer illusion on repeated trials: A study of crossmodal transfer. Quarterly Journal of Experimental Psychology, 15, 125-131. SCHEFF', M. (1959). The analysis of variance. New York: Wiley.

Simion, F., \& Bagnara S. (1982). Le principali dicotomie proposte per la spiegazione delle asimmetrie emisferiche. In C. Umiltà (Ed.), Neuropsicologia sperimentale. Milan: Franco Angeli.

Umiltà, C. A. (1982). Specializzazione funzionale degli emisferi cerebrali e modi di rappresentazione dell' informazione. In C. Umiltà (Ed.), Neuropsicologia sperimentale. Milan: Franco Angeli.

Wenderoth, P., \& Johnson, M. (1981). Are the obtuse angles the key components of the Poggendorf illusion? Perception, 10, 165-172.

WitELSON, S. (1974). Hemispheric specialization for linguistic and nonlinguistic tactual perception using a dichotomous stimulation technique. Cortex, 10, 3-17.

WITHAKER, L. (1982). Stimulus-response compatibility for left-right discrimination as a function of stimulus position. Journal of Experimental Psychology: Human Perception \& Performance, 8, 865-874.

\section{NOTES}

1. For overall analyses, in view of post hoc comparisons, the significance level was set equal to $10 \%$ (see, e.g., Scheffé, 1959, p. 71).

2. For a total $10 \%$ each of four nested hypotheses was tested with a significant level of 2.5\% (Marascuilo \& Levin, 1970; Miller, 1966).

(Manuscript received May 6, 1985; revision accepted for publication April 17, 1986.) 